\title{
ION IMPLANTATION DOPING AND HIGH TEMPERATURE ANNEALING OF GaN
}

\author{
J. C. ZOLPER, ${ }^{\mathrm{a}}$ M. HAGEROTT CRAWFORD, ${ }^{\mathrm{a}}$ A. J. HOWARD, a,c \\ S. J. PEARTON, b C. R. ABERNATHY, b C. B. VARTULI, ${ }^{b}$ C. YUAN, \\ R. A. STALL, ' J. RAMERd, S. D. HERSEE, and R. G. WILSONe
}

aSandia National Laboratories, Albuquerque, NM 87185-0603,

bUniversity of Florida, Department of Materials Science and

Engineering, Gainesville, FL 32611

c Emcore Corp., Somerset, NJ 08873

d University of New Mexico, Albuquerque, NM 87131

e Hughes Research Laboratory, Malibu CA 90265

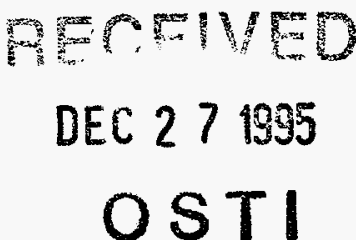

\begin{abstract}
The III-V nitride-containing semiconductors InN, GaN, and $\mathrm{AlN}$ and their ternary alloys are the focus of extensive research for application to visible light emitters and as the basis for high temperature electronics. Recent advances in ion implantation doping of $\mathrm{GaN}$ and studies of the effect of rapid thermal annealing up to $1100^{\circ} \mathrm{C}$ are making new device structures possible. Both pand n-type implantation doping of $\mathrm{GaN}$ has been achieved using $\mathrm{Mg}$ coimplanted with $\mathrm{P}$ for $\mathrm{p}$-type and $\mathrm{Si}$-implantation for $\mathrm{n}$-type. Electrical activation was achieved by rapid thermal anneals in excess of $1000^{\circ} \mathrm{C}$. Atomic force microscopy studies of the surface of $\mathrm{GaN}$ after a series of anneals from 750 to $1100^{\circ} \mathrm{C}$ shows that the surface morphology gets smoother following anneals in Ar or $\mathrm{N}_{2}$. The photoluminescence of the annealed samples also shows enhanced bandedge emission for both annealing ambients. For the deep level emission near $2.2 \mathrm{eV}$, the sample annealed in $\mathrm{N}_{2}$ shows slightly reduced emission while the sample annealed in Ar shows increased emission. These annealing results suggest a combination of defect interactions occur during the high temperature processing.

*This work was performed at Sandia National Laboratories and was supported by the US/DOE under contract DE-Ac04-94AL85000.
\end{abstract} INTRODUCTION

The III-V nitride-containing semiconductors InN, GaN, and AlN and their ternary alloys are attracting renewed interest for application to visible light emitters 1,2 and as the basis for high temperature electronics. 3-5 Their attractive material properties include bandgaps ranging from $1.9 \mathrm{eV}(\mathrm{InN})$ to $6.2 \mathrm{eV}(\mathrm{AlN})$, an energy gap $(\mathrm{Eg}(\mathrm{GaN})=3.39 \mathrm{eV})$ close to the short wavelength region of the visible spectrum, high breakdown fields, high saturation drift velocities and relatively high carrier mobilities. ${ }^{6}$

There have been limited reports of the implantation properties of the III-V nitrides. 7 Early work by Pankove ${ }^{8}$ focused on the optical properties of $\mathrm{GaN}$ implanted with an array of elements while Khan investigated the implantation of $\mathrm{Be}$ or $\mathrm{N}$ in $\mathrm{GaN}^{9}$ and $\mathrm{AlGaN} \mathrm{N}^{10}$ to improve Schottky barrier characteristics. Recently there have been reports on the implant isolation properties of III-Nitride materials $11,12,13$ but there has been only one report of the achievement of implantation doping of $\mathrm{GaN} .14$ In this work we report in more detail on the 


\section{DISCLAMIER}

Portions of this document may be illegible in electronic image products. Images are produced from the best available original document. 
properties of implantation doping in GaN. Specifically, Hall data for the sheet carrier concentration versus annealing temperature is reported. Variable temperature Hall data is reported and used to estimate the ionization energy levels for implanted $\mathrm{Mg}$ and $\mathrm{Si}$ in GaN. In addition, secondary ion mass spectroscopy (SIMS) data is presented for as-implanted and annealed samples to study the redistribution properties of implanted $\mathrm{Mg}$ and $\mathrm{Si}$ in $\mathrm{GaN}$. Furthermore, since an implant activation anneal in excess of $1000^{\circ} \mathrm{C}$ is required to achieve electrical activation, data for the effect of such an anneal on the morphology and luminescence properties of $\mathrm{GaN}$ is presented. Results are also given for ohmic contact formation to Si-implanted GaN.

\section{EXPERIMENTAL}

The GaN layers used in the implant doping experiments were 1.5 to $2.0 \mu \mathrm{m}$ thick grown on c-plane sapphire substrates by metalorganic chemical vapor deposition (MOCVD) in a multiwafer rotating disk reactor at $1040^{\circ} \mathrm{C}$ with a $\sim 20 \mathrm{~nm} \mathrm{GaN}$ buffer layer grown at 530 ${ }^{\circ} \mathrm{C} .15$ The GaN layers were unintentionally doped, with background n-type carrier concentrations $\leq 5 \times 10^{16} \mathrm{~cm}^{-3}$. The as-grown layers had featureless surfaces and were transparent with a strong bandedge luminescence at $3.484 \mathrm{eV}$ at $14 \mathrm{~K}$. The $\mathrm{GaN}$ layers used in the annealing experiments were also grown by MOCVD but in a RF-heated, horizontal geometry reactor consisting of a double walled deposition chamber, a rectangular-section flow-liner, and an uncoated graphite susceptor angled for optimum uniformity. 16 This GaN

was grown on solvent cleaned, a-plane [1120] oriented, sapphire substrates. The growth sequence involved a thin $\mathrm{GaN}$ buffer at $480^{\circ} \mathrm{C}$ followed by a $\sim 5 \mu \mathrm{m} \mathrm{GaN}$ layer at $1025^{\circ} \mathrm{C}$ with a $2 \mu \mathrm{m} / \mathrm{hr}$ growth rate. The as-grown $\mathrm{GaN}$ is colorless, has a specular morphology, shows a typical $n$-type background doping in the $6 \times 10^{16} \mathrm{~cm}^{-3}$ to $3 \times 10^{17} \mathrm{~cm}^{-3}$ range, a mobility between 200 and $600 \mathrm{~cm}^{2} / \mathrm{V}$-s, and an x-ray rocking curve FWHM of approximately 200 arc seconds.

For implantation doping, the samples were implanted with either ${ }^{28} \mathrm{Si}\left(5 \times 10^{14} \mathrm{~cm}^{-2}\right.$, $200 \mathrm{keV}),{ }^{24} \mathrm{Mg}\left(5 \times 10^{14} \mathrm{~cm}^{-2}, 180 \mathrm{keV}\right)$, or ${ }^{24} \mathrm{Mg}+31 \mathrm{P}\left(5 \times 10^{14} \mathrm{~cm}^{-2}, 180 / 250 \mathrm{keV}\right)$. The samples were annealed from 700 to $1100^{\circ} \mathrm{C}$ for $10 \mathrm{~s}$ in a SiC coated graphite susceptor in flowing $\mathrm{N}_{2}$. Electrical characterization was performed by van der Pauw Hall measurements using alloyed $\left(350^{\circ} \mathrm{C}, 10 \mathrm{~s}\right) \mathrm{HgIn}$ contacts at the corners of each sample.

For the annealing experiment, the anneals were done in a similar fashion as above except for $15 \mathrm{~s}$ and in one of three ambients: $4 \% \mathrm{H}_{2}: 96 \% \mathrm{~N}_{2}, \mathrm{Ar}$, or $\mathrm{N}_{2}$. The samples surface morphology were characterized by atomic force microscopy (AFM) with a Digital Instruments Dimension 3000 AFM operating in the tapping mode with a silicon tip by taking $10 \mu \mathrm{m} \times 10 \mu \mathrm{m}$ images at three points on each sample. Each image was then analyzed for the RMS surface roughness. The as-grown material and the $\mathrm{Ar}$ and $\mathrm{N}_{2} 1100^{\circ} \mathrm{C}$ annealed samples were also characterized by photoluminescence using a $10 \mathrm{~mW}$ HeCd laser $(325 \mathrm{~nm})$ excitation source with the spectra taken at $15 \mathrm{~K}$.

\section{RESULTS AND DISCUSSION}

Figure $1(a, b)$ shows the sheet electron and hole concentration versus activation annealing temperature for $\mathrm{Si}, \mathrm{Mg}, \mathrm{Mg}+\mathrm{P}$, or unimplanted $\mathrm{GaN}$. For Si-implantation (Fig. 1a) electrical activation first occurs after a $1050{ }^{\circ} \mathrm{C}$ anneal with a $\sim 16$ fold increase in sheet electron concentration which increases by a additional factor of 5 after a $1100^{\circ} \mathrm{C}$ anneal. Coimplantation of $\mathrm{P}$ with $\mathrm{Mg}$ was found to be necessary to achieve p-type material after a 1050 ${ }^{\circ} \mathrm{C}$ anneal as evident in Fig. 1b. In contrast, the $\mathrm{Mg}$-only sample remains n-type and shows little difference from the unimplanted sample. The effect of the P co-implantation may be 
explained by a reduction of $\mathrm{N}$-vacancies or an increase in Ga-vacancies leading to a higher probability of $\mathrm{Mg}$ occupying a Ga-site. Co-implantation of $\mathrm{P}$ has also been shown to be effective in enhancing activation and reducing diffusion for p-type implantation in GaAs. 17,18,19 Figure 2a,b shows an Arrhenius plot of the sheet electron concentration and the resistance/temperature product for $\mathrm{Si}$-implanted $\mathrm{GaN}$ after a $1100^{\circ} \mathrm{C}$ anneal. Both Arrenhius plots for Si are included in Fig. 2, since there is some discussion regarding the possibility of two-band conduction in GaN and its potential effect on the extracted ionization energy for n-type conduction. 20 By fitting the data of Fig. 2, ionization levels for Siimplanted GaN of 61 or $29 \mathrm{meV}$ are estimated. These values are in the range reported for epitaxial Si-doped GaN.21 Figure 2c shows the Arrhenius plot for the sheet hole concentration for $\mathrm{Mg}+\mathrm{P}$ implanted $\mathrm{GaN}$ annealed at $1100^{\circ} \mathrm{C}$ from which an ionization of 171 $\mathrm{meV}$ is estimated. This also is consistent with the literature values for $\mathrm{Mg}$-doped $\mathrm{GaN} .2$
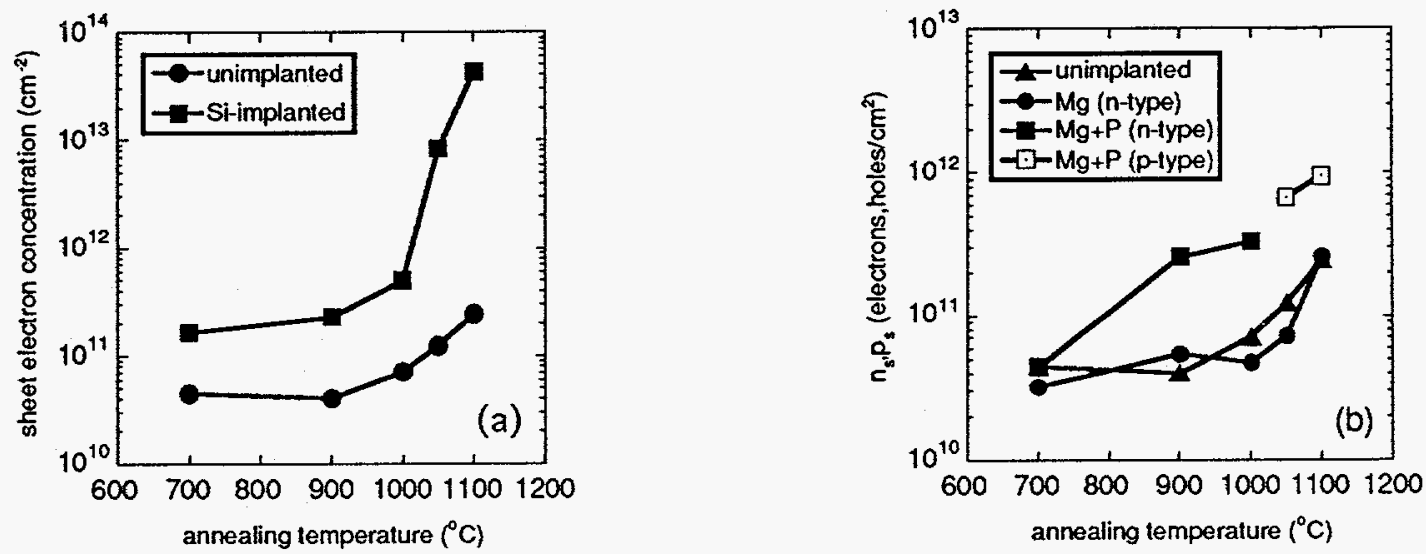

FIG 1. Sheet carrier concentration versus annealing temperature for unimplanted and a) Siimplanted or b) $\mathrm{Mg}$ and $\mathrm{Mg}+\mathrm{P}$ implanted $\mathrm{GaN}$.
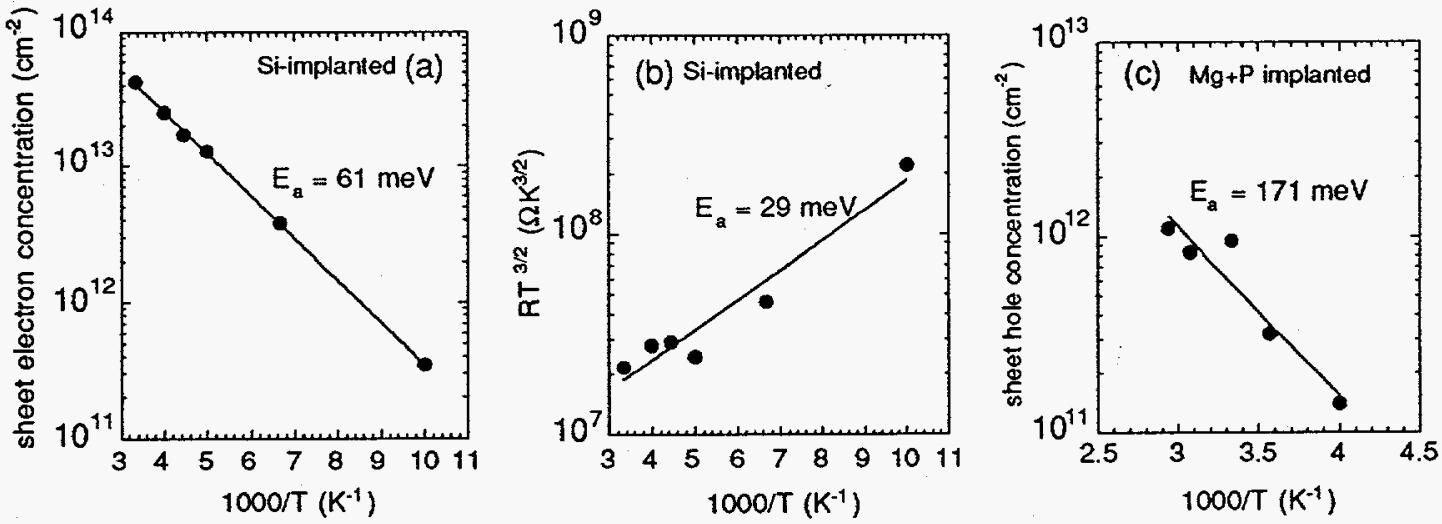

FIG 2. Arrhenius plots of a) the sheet electron concentration and $b$ ) the resistance/temperature product for Si-implanted and c) the sheet hole concentration for $\mathrm{Mg}$-implanted $\mathrm{GaN}$ annealed at $1100^{\circ} \mathrm{C}$.

When applying ion implantation doping to device structures, knowledge of impurity redistribution during the activation anneal process is needed. Figure $3 \mathrm{a}, \mathrm{b}$ shows the SIMS profiles for $\mathrm{Mg}$ and $\mathrm{Si}$ implanted $\mathrm{GaN}$ either as implanted or after a $15 \mathrm{~s}, 1050$ or $1150^{\circ} \mathrm{C}$ anneal. For $\mathrm{Mg}$, the annealed samples show a slight shift towards the surface that is estimated to be $50 \mathrm{~nm}$ near the profile peak. Based on a $50 \mathrm{~nm}$ diffusion length, an upper limit on the diffusivity of $\mathrm{Mg}$ in $\mathrm{GaN}$ at $1150{ }^{\circ} \mathrm{C}$ of $6.75 \times 10^{-13} \mathrm{~cm}^{2} / \mathrm{s}$ is estimated. Profiles for $\mathrm{Mg}$ coimplanted with $\mathrm{P}$ gave similar results. For $\mathrm{Si}$ (Fig $3 \mathrm{~b}$ ) no measurable redistribution has occurred after a $1050^{\circ} \mathrm{C}$ anneal. Using a conservative estimate of the depth resolution of the 
SIMS measurement of $20 \mathrm{~nm}$, an upper limit of $2.7 \times 10^{-13} \mathrm{~cm}^{2} / \mathrm{s}$ is estimated for the diffusivity of $\mathrm{Si}$ in $\mathrm{GaN}$ at $1050^{\circ} \mathrm{C}$.
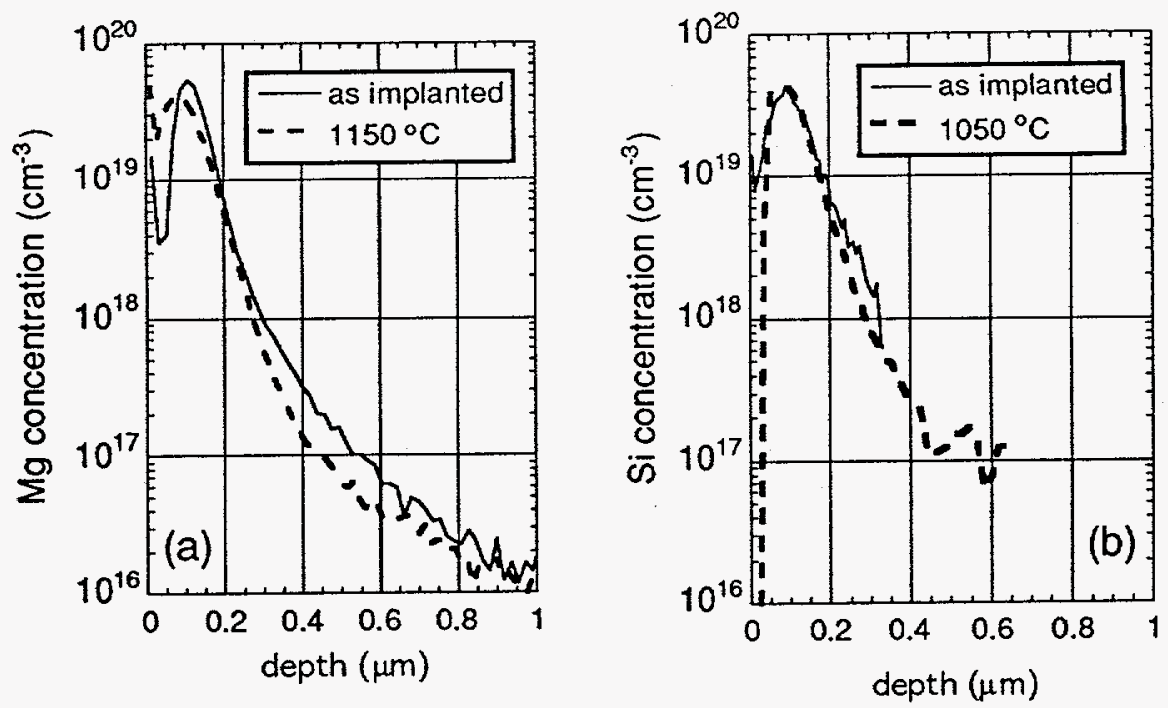

FIG 3: SIMS plots for a) Mg-implanted $\left(5 \times 10^{14}, 100 / 140 \mathrm{keV}\right)$ or b) Si-implanted $\left(5 \times 10^{14}\right.$, $100 \mathrm{keV}) \mathrm{GaN}$ either as implanted or annealed at the temperature listed in the legend.

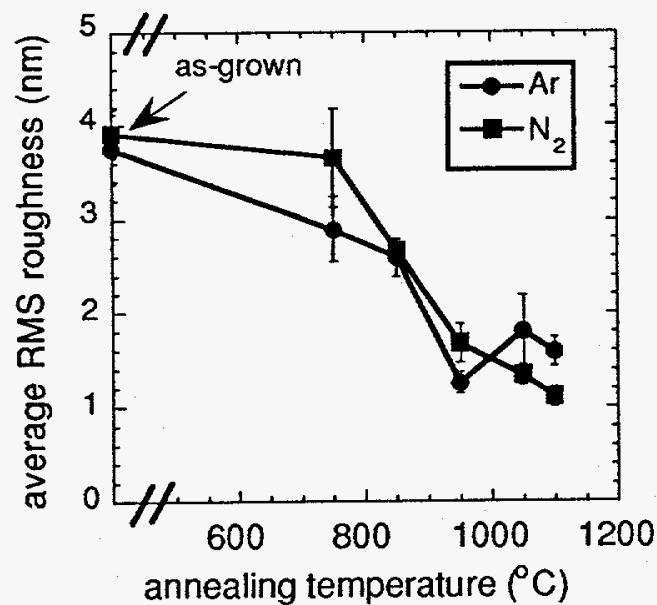

FIG 4: Average RMS roughness of GaN versus annealing temperature for anneals in $\mathrm{Ar}$ or $\mathrm{N}_{2}$.

Turning to the effect of high temperature anneals on the surface morphology of GaN films, Fig. 4 shows the evolution of the root-mean-square (RMS) surface roughness versus annealing temperature for samples annealed in Ar or $\mathrm{N}_{2}$. The roughness of these samples decreases with increasing annealing temperature. Figure 5 shows three dimensional AFM images of the as-grown and $1100{ }^{\circ} \mathrm{C}, \mathrm{N}_{2}$ annealed samples. The annealed sample is seen to be smoother with less fine structure. 22 Samples annealed in forming gas $\left(4 \% \mathrm{H}_{2}: 96 \% \mathrm{~N}_{2}\right)$ were also studied and showed visual evidence of decomposition via Ga-droplet or Ga-puddle formation on the surface. Therefore, a valid assessment of the surface roughness of these samples could not be made due to the Ga-rich regions and thus data for forming gas annealed samples are not included in Fig. 4.

\section{DISCLAIMER}

This report was prepared as an account of work sponsored by an agency of the United States Government. Neither the United States Government nor any agency thereof, nor any of their employees, makes any warranty, express or implied, or assumes any legal liability or responsibility for the accuracy, completeness, or usefulness of any information, apparatus, product, or process disclosed, or represents that its use would not infringe privately owned rights. Reference herein to any specific commercial product, process, or service by trade name, trademark, manufacturer, or otherwise does not necessarily constitute or imply its endorsement, recommendation, or favoring by the United States Government or any agency thereof. The views and opinions of authors expressed herein do not necessarily state or reflect those of the United States Government or any agency thereof. 


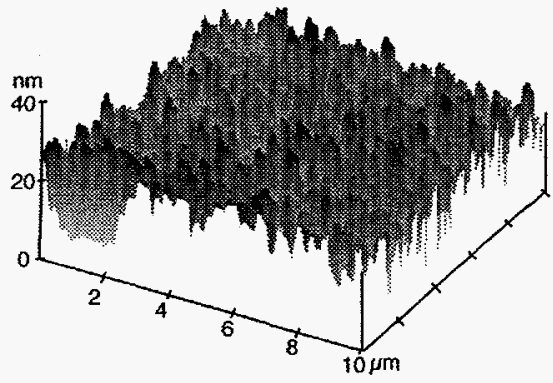

(a)

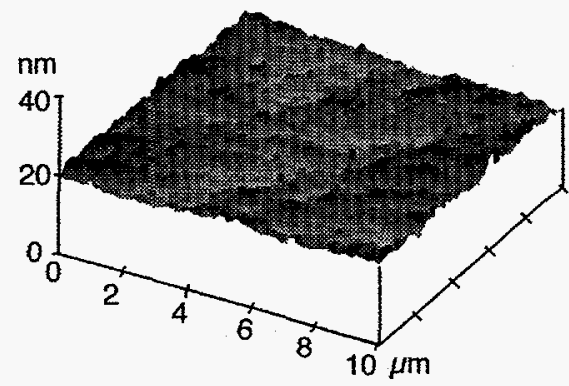

(b)

FIG 5: Three dimensional AFM images of $\mathrm{GaN}$ a) as-grown and b) after a $15 \mathrm{~s}, 1100$ ${ }^{\circ} \mathrm{C}$ anneal in $\mathrm{N}_{2}$.

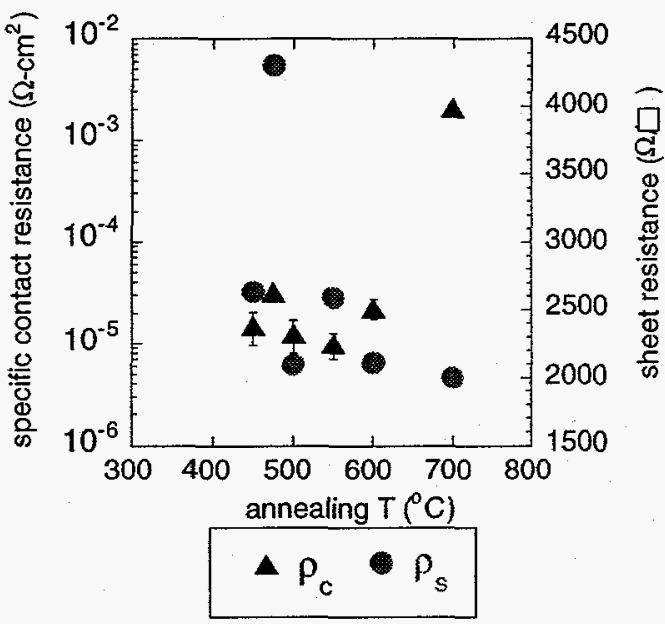

FIG 6. Specific contact resistance of $\mathrm{Ti} / \mathrm{Al}$ and sheet resistance versus contact annealing temperature for Si-implanted $\mathrm{GaN}\left(5 \times 10^{14}\right.$, $\left.40 \mathrm{keV}, 7.5 \times 10^{14}, 100 \mathrm{keV}\right)$ annealed at $1150{ }^{\circ} \mathrm{C}$ for $15 \mathrm{~s}$.
To further understand the effect of high temperature annealing on GaN, photoluminescence measurements were performed on as-grown and annealed samples. ${ }^{22}$ Samples annealed at $1100{ }^{\circ} \mathrm{C}$ in $\mathrm{Ar}$ or $\mathrm{N}_{2}$ demonstrated stronger bandedge emission ( $2 \mathrm{x}$ for $\mathrm{Ar}, 4 \mathrm{x}$ for $\mathrm{N}_{2}$ ) than the asgrown sample. This suggests that nonradiative defect levels are being removed by the annealing process. The annealed samples also showed more intensity modulation of the Fabry-Perot interference fringes associated with the deep level emission. We attribute the enhanced interference to the smoother surfaces of the annealed samples as seen from the AFM data of Figs. 4 and 5 . Finally, both annealed samples have higher ratios of the bandedge to deep level emission than the as-grown sample. Improvements in this ratio are often taken to correspond to improved material quality. Further structural and chemical analysis is required to fully understand the mechanisms responsible for the material improvements resulting from the high temperature anneals. In particular, since studies on other compound semiconductors have shown that changes in photoluminescence properties resulting from thermal treatments often depend on the condition of the starting material, more work is needed to correlate the luminescence improvements with the characteristics of the as-grown material.

Finally, we have done preliminary work on ohmic contact formation to n-type implantation doped GaN. Figure 6 shows the specific contact resistance and sheet resistance of Si-implanted GaN contacted with $\mathrm{Ti} / \mathrm{Al}$ (20 $\mathrm{nm} / 200 \mathrm{~nm}$ ) metallization versus the contact annealing temperature. A minimum specific contact resistance of $1 \times 10^{-5} \Omega-\mathrm{cm}^{2}$ was realized after a $550{ }^{\circ} \mathrm{C}$ anneal which is in the range typically reported for contacts to n-type GaN. Further optimization of the implant and anneal to reduce the sheet resistance of the implanted region will improve this contact resistance.

\section{CONCLUSION}

Ion implantation is expected to play an enabling role in the realization of many high performance devices in the III-Nitrides as it has in other mature semiconductor material systems. To this end, we have reported on the realization of $n$ - and p-type doping of GaN by 
implantation of $\mathrm{Si}$ and $\mathrm{Mg}+\mathrm{P}$, respectively. The high temperature anneal required for implant activation was also shown to cause minimal redistribution of Si and $\mathrm{Mg}$.

Acknowledgments: The portion of this work performed at Sandia National Laboratories was supported by the U.S. Department of Energy under contract \# DE-AC04-94AL85000. The work at the University of Florida is partially supported by a National Science Foundation grant (DMR-9421109) and a University Research Initiative grant from ONR (N00014-92-51895). The work at EMCORE was supported by BMDO-IST managed by M. Yoder at ONR. The SIMS work was performed at Hughes and was supported by ARO (Dr. J. M. Zavada). Work at Un. of New Mexico was supported by ARPA. The technical support of J. Escobedo at Sandia with implantation and annealing and the support of the MicroFabritech facility at UF is greatly appreciated.

\section{References}

1 S. Nakamura, T. Mukai, and M. Senoh, Appl. Phys. Lett., 64, 1687 (1994).

2 I. Akasaki, H. Amano, M. Kito, and K. Hiramatsu, J. Lumin. 48/49, 666 (1991).

3 S. C. Binari, L. B. Rowland, W. Kruppa, G. Kelner, K. Doverspike, and D. K. Gaskill, Electronics Lett., 30, 1248 (1994).

4 M. A. Kahn, J. N. Kuznia, D. T. Olsen, W. J. Schaff, J. W. Burm, and M. S. Shur, Appl. Phys. Lett., 65, 1121 (1994).

5 T. P. Chow and R. Tyagi, IEEE Trans. Electron. Dev., 41, 1481 (1994).

6 S. Strite and H. Morkoç, J. Vac. Sci. Technol. B 10, 1237 (1992).

7 J. C. Zolper, M. Hagerott Crawford, S. J. Pearton, C. R. Abernathy, C. B. Vartuli, C. Yuan, and R. A. Stall, J. Elec. Mat. in press.

8 J. I. Pankove and J. A. Hutchby, J. Appl. Phys., 47, 5387 (1976).

9 M. A. Khan, R. A. Skogman, R. G. Schule, and M. Gershenzon, Appl. Phys. Lett., 42, 430 (1983).

10 M. A. Khan, R. A. Skogman, R. G. Schule, and M. Gershenzon, Appl. Phys. Lett., 43, 492 (1983).

11 S. J. Pearton, C. R. Abernathy, P. W. Wisk, W. S. Hobson, and F. Ren, Appl. Phys. Lett., 63, 1143 (1993).

12 J. C. Zolper, S. J. Pearton, C. R. Abernathy, and C. B. Vartuli, Appl. Phys. Lett. 66, 3042 (1995).

13 C. B. Vartuli, S. J. Pearton, C. R. Abernathy, J. D. MacKenzie, and J. C. Zolper, submitted to J. Vac. Science and Technology

14 S. J. Pearton, C. B. Vartuli, J. C. Zolper, C. Yuan, and R. A. Stall, Appl. Phys. Lett. 67, 1435 (1995).

15 C. Yuan, T. Salagaj, A. Gurary, P. Zawadzki, C. S. Chern, W. Kroll, R. A. Stall, Y. Li, M. Schurman, C.-Y. Hwang, W. E. Mayo, Y. Lu, S. J. Pearton, S. Krishnankutty, and R. M. Kolbas, J. Electrochem. Soc. 142, L163 (1995).

16 S. D. Hersee, J. Ramer, K. Zheng, C. Kranenberg, K. Malloy, M. Banas, and M. Goorsky, J. Elec. Mat. 24, 1519 (1995).

17 K. K. Patel and B. J. Sealy, Appl. Phys. Lett. 481467 (1986).

18 M. E. Sherwin, J. C. Zolper, A. G. Baca, T. J. Drummond, R. J. Shul, A. J. Howard, D. J. Rieger, R. P Schneider, and J. F. Klem, J. Elec. Mater. 15, 809 (1994).

19 J. C. Zolper, A. G. Baca, M. E. Sherwin, and R. J. Shul, Elec. Letts. 31, 923 (1995).

20 R. J. Molnar, T. Lei, and T. D. Moustakas, Appl. Phys. Lett. 6272 (1993).

21 J. G. Kim, A. C. Frenkel, H. Liu, and R. M. Park, Appl. Phys. Lett. 65, 91 (1994).

22 J. C. Zolper, M. Hagerott Crawford, A. J. Howard, J. Ramer, and S. D. Hersee, Appl. Phys. Lett. in press. 